\title{
Risk factors and long-term implications of unplanned conversion during laparoscopic liver resection for hepatocellular carcinoma located in anterolateral liver segments
}

Hyojin Shin, Jai Young Cho, Ho-Seong Han, Yoo-Seok Yoon, Hae Won Lee, Jun Suh Lee, Boram Lee, Moonhwan Kim, Yeongsoo Jo

Division of Hepatobiliary and Pancreas Surgery, Department of Surgery, Seoul National University Bundang Hospital, Seongnam, Korea

Purpose: The impact of conversion on perioperative and long-term oncologic outcomes is controversial. Thus, we compared these outcomes between laparoscopic (Lap), unplanned conversion (Conversion), and planned open (Open) liver resection for hepatocellular carcinoma (HCC) located in anterolateral (AL) liver segments and aimed to identify risk factors for unplanned conversion.

Methods: We retrospectively studied 374 patients (Lap, 299; Open, 62; Conversion, 13) who underwent liver resection for HCC located in AL segments between 2004 and 2018.

Results: Compared to the Lap group, the Conversion group showed greater values for operation time ( $p<$ $0.001)$, blood loss $(p=0.021)$, transfusion rate $(p=0.009)$, postoperative complication rate $(p=0.008)$, and hospital stay $(p=0.040)$, with a lower $\mathrm{R} 0$ resection rate $(p<0.001)$ and disease-free survival $(p=0.001)$. Compared with the Open group, the Conversion group had a longer operation time $(p=0.012)$ and greater blood loss $(p=0.024)$. Risk factors for unplanned conversion were large tumor size (odds ratio $[\mathrm{OR}], 1.35$; 95\% confidence interval [CI], 1.05-1.74; $p=0.020$ ), multiple tumors (OR, 5.95; 95\% CI, 1.45-24.39; $p=0.013$ ), and other organ invasion (OR, 15.32; 95\% CI, 1.80-130.59; $p=0.013)$.

Conclusion: In conclusion, patients who experienced unplanned conversion during LLR for HCC located in AL segments showed poor perioperative and long-term outcomes compared to those who underwent planned laparoscopic and open liver resection. Therefore, open liver resection should be considered in patients with risk factors for unplanned conversion.

Keywords: Hepatectomy, Laparoscopy, Conversion to open surgery, Survival, Risk factors
Received August 17, 2021

Revised 1st October 9, 2021 2nd October 19, 2021

Accepted October 20, 2021

Corresponding author Jai Young Cho

Department of Surgery, Seoul

National University Bundang

Hospital, 82 Gumi-ro 173beon-gil, Bundang-gu, Seongnam 13620, Korea Tel: +82-31-787-7098

Fax: +82-31-787-4078

E-mail: jychogs@gmail.com ORCID:

https://orcid.org/0000-0002-1376-956X

This is an Open Access article distributed under the terms of the Creative Commons Attribution Non-Commercial License (http:// creativecommons.org/licenses/by-nc/4.0/) which permits unrestricted non-commercial use, distribution, and reproduction in any medium, provided the original work is properly cited.

Copyright (C) The Korean Society of Endoscopic and Laparoscopic Surgeons.

\section{INTRODUCTION}

Laparoscopic liver resection (LLR) is widely accepted as a safe and feasible treatment for hepatocellular carcinoma (HCC) [1]. It is considered the standard procedure for left lateral sectionectomy [2] and minor hepatectomy of solitary lesions $\leq 5 \mathrm{~cm}$ in diameter located in the peripheral area of anterolateral $(\mathrm{AL})$ liver segments (segments 2, 3, 4b, 5, and 6) [3,4]. Previous studies have shown that LLR is associated with decreased blood loss, transfu- sion rate, and postoperative complications, with similar operation time, R0 status, and short-term oncologic outcomes compared to open liver resection (OLR) [5,6].

With the accumulation of LLR experience and improvement in laparoscopic devices, indications for LLR have expanded, and LLR has become more popular [7,8]. However, unplanned conversion to OLR during LLR is occasionally inevitable owing to the difficulty to achieve hemostasis due to concurrent liver cirrhosis with HCC, limited visibility, and reduced ability to approach 
deeper regions of the liver [9].

Several studies have reported that conversion is associated with poor perioperative outcomes [10-18], with conversion rates ranging from $0 \%$ to $55 \%$ [19]. However, the impact of conversion on long-term oncologic outcomes is controversial, and there are a limited number of published studies on this topic $[13,14,17]$. Moreover, most of the studies included lesions located in posterosuperior (PS) segments of the liver, which are known to be notably challenging for performing LLR [3], which may lead to bias in identifying risk factors for unplanned conversion. Therefore, this study aimed to compare unplanned conversion from LLR to OLR for HCC located in AL segments of the liver in terms of perioperative and long-term oncologic outcomes. In addition, we attempted to identify the risk factors for unplanned conversion.

\section{MATERIALS AND METHODS}

We retrospectively reviewed the data of all consecutive patients who underwent liver resection for HCC located in AL segments of the liver (segments 2, 3, 4b, 5, and 6) at our institution between January 2004 and October 2018. Initially, a laparoscopic approach was planned for 312 patients. Among them, 299 patients successfully underwent LLR (Lap group) and 13 patients underwent unplanned conversion (Conversion group). Patients who underwent planned OLR (Open group, $\mathrm{n}=62$ ) were also analyzed.

The decision to perform LLR or OLR was made based on

Table 1. Preoperative characteristics of patients who underwent laparoscopic liver resection (Lap group) and unplanned conversion (Conversion group)

\begin{tabular}{|c|c|c|c|}
\hline Variable & Lap group & Conversion group & $p$ value \\
\hline No. of patients & 299 & 13 & \\
\hline Age (yr) & $59.05 \pm 11.62$ & $57.62 \pm 9.13$ & 0.661 \\
\hline Sex & & & 0.159 \\
\hline Male & $225(75.3)$ & $12(92.3)$ & \\
\hline Female & $74(24.7)$ & $1(7.7)$ & \\
\hline Body mass index $\left(\mathrm{kg} / \mathrm{m}^{2}\right)$ & $24.31 \pm 3.89$ & $23.72 \pm 3.21$ & 0.588 \\
\hline Child-Pugh classification & & & 0.503 \\
\hline$A$ & $289(96.7)$ & $13(100)$ & \\
\hline $\mathrm{B}$ & $10(3.3)$ & $0(0)$ & \\
\hline C & $0(0)$ & $0(0)$ & \\
\hline Hepatitis & & & 0.851 \\
\hline HBV & $213(71.5)$ & $10(76.9)$ & \\
\hline $\mathrm{HCV}$ & $15(5.0)$ & $0(0)$ & \\
\hline Both positive & $2(0.7)$ & $0(0)$ & \\
\hline Both negative & $69(23.1)$ & $3(23.1)$ & \\
\hline History of abdominal surgery & $61(20.4)$ & $1(7.7)$ & 0.261 \\
\hline Alpha-fetoprotein & $698.81 \pm 5,599.86$ & $290.89 \pm 449.46$ & 0.848 \\
\hline Prior TACE & $63(21.1)$ & $4(36.4)$ & 0.226 \\
\hline Prior RFA & $28(9.4)$ & $0(0)$ & 0.287 \\
\hline Tumor size (cm) & $2.82 \pm 1.52$ & $4.11 \pm 2.01$ & 0.009 \\
\hline No. of tumors & & & 0.001 \\
\hline Solitary & $271(90.6)$ & $8(61.5)$ & \\
\hline Multiple & $28(9.4)$ & $5(38.5)$ & \\
\hline Vascular invasion & $4(1.3)$ & $0(0)$ & 0.675 \\
\hline Other organ invasions & $5(1.7)$ & $2(15.4)$ & 0.001 \\
\hline
\end{tabular}

Values are presented as number only, number (\%), or mean \pm standard deviation.

HBV, hepatitis B virus; HCV, hepatitis C virus; TACE, transarterial chemoembolization; RFA, radiofrequency ablation.

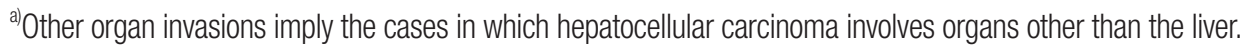


tumor size, location, and hepatic function. During the early phase of our center, the laparoscopic approach was considered for patients with solitary lesions (sized $\leq 5 \mathrm{~cm}$ ) located in the peripheral area of AL segments. For left lateral sectionectomy, the laparoscopic approach was considered the standard practice. Regarding major liver resection, the laparoscopic approach is primarily considered because evidences that advocate the feasibility and safety of the laparoscopic approach for major liver resection have been accumulated, in addition to our center's experience. With the increased experience of LLR at our center, indications for LLR have largely extended beyond the standard indications in terms of size and extent as long as safe and complete resection is expected. However, for patients with more than four tumors or tumor sized $>10 \mathrm{~cm}$ in diameter, open surgery was planned considering insufficient operative field and increased risk of tumor spillage. Single- or multi-port access was applied according to the surgeon's preference or feasibility considering the tumor location.

All statistical analyses were performed using IBM SPSS version 22.0 (IBM Corp., Armonk, NY, USA). Continuous variables are represented as mean \pm standard deviation, and categorical variables are represented as number (\%). The Student $t$ test or Mann-Whitney $U$ test (for nonparametric analysis) was used to compare continuous data, while the chi-square test or Fisher exact test was used to compare categorical data. Multivariate logistic regression analysis was utilized to identify independent risk factors for unplanned conversion. The overall survival (OS) and disease-free survival (DFS) rates were analyzed using the KaplanMeier method, and the differences between the groups were compared using the log-rank test. Statistical significance was set at $p<0.05$.

\section{RESULTS}

A total of 374 patients underwent liver resection for HCC located in AL liver segments. Initially, planned OLR was performed in 62 patients, and a laparoscopic approach was planned in 312 patients. Among them, 299 patients successfully underwent LLR, while unplanned conversion was required in 13 patients, with a conversion rate of $4.2 \%$. Bleeding $(n=9,69.2 \%)$ was the most common cause of conversion followed by adhesion $(n=2,15.4 \%)$, deep tumor location $(n=1,7.7 \%)$, and oncologic concern $(n=1$, 7.7\%). There was no postoperative mortality within 3 months.

\section{Laparoscopy vs. conversion}

Comparisons of preoperative and patient characteristics between the Lap and Conversion groups are detailed in Table 1. The two groups were similar with regard to age, sex, body mass index (BMI), and history of abdominal surgery. There was also no difference in terms of the Child-Pugh classification, viral hepatitis

Table 2. Patients with other organ invasion and operation name

\begin{tabular}{cll}
\hline Group & Other organ invasions & \\
\hline Lap & Operation name \\
1 & Stomach & Laparoscopic S3 tumorectomy, gastric wedge resection \\
2 & Gastrohepatic ligament & Laparoscopic left lateral sectionectomy \\
3 & Gall bladder & Laparoscopic left hemihepatectomy, cholecystectomy \\
4 & Left hepatic duct & Laparoscopic left hemihepatectomy, cholecystectomy \\
5 & Left hepatic duct & Laparoscopic left hemihepatectomy \\
\hline Conversion & & \\
1 & Right Gerota's fascia & Open conversion S6 segementectomy, S5 tumorectomy \\
2 & Duodenum & Open conversion S5 tumorecotmy, duodenal serosal repair \\
\hline Open & & \\
1 & Right adrenal gland & S6 tumorectomy, right partial adrenalectomy \\
2 & gall bladder & S5 tumorectomy, cholecystectomy \\
3 & Colon & Palliative bisegmentectomy (S5, 6), tumorectomy (S2), right hemicolectomy, cholecystectomy \\
4 & Left hepatic duct & Left hemihepatectomy, caudate lobectomy, hepaticojejunostomy, cholecystectomy \\
5 & Left hepatic duct & Left hemihepatectomy, cholecystectomy \\
6 & Left hepatic duct & Left hemihepatectomy, caudate lobectomy, cholecystectomy \\
\hline
\end{tabular}

Lap group, the patients underwent laparoscopic liver resection; Conversion group, the patients underwent unplanned conversion; Open group, the patients underwent planned open liver resection. 
status, alpha-fetoprotein level, and percentage of previous treatment with transarterial chemoembolization and radiofrequency ablation. However, the Conversion group had a significantly larger tumor size $(2.82 \pm 1.52 \mathrm{~cm}$ vs. $4.11 \pm 2.01 \mathrm{~cm}, p=0.009)$, greater percentage of multiple tumors $(9.4 \%$ vs. $38.5 \%, p=0.001)$, and presence of other organ invasion (1.7\% vs. $15.4 \%, p=0.001)$. However, the presence of other organ invasion did not always result in resection of the invaded organ (Table 2).

Table 3 summarizes the perioperative and pathological outcomes of the patients. Conversion was associated with a longer mean operation time $(300.00 \pm 142.08$ minutes vs. $182.03 \pm 105.65$ minutes, $p<0.001)$ and postoperative hospital stay $(10.38 \pm 5.69$ days vs. $6.48 \pm 6.71$ days, $p=0.040$ ). Estimated blood loss was greater $(1,596.15 \pm 1,604.87 \mathrm{~mL}$ vs. $411.35 \pm 614.33 \mathrm{~mL}, p=0.021)$ in the Conversion group than in the Lap group, and this resulted in higher percentage of blood transfusion ( $23.1 \%$ vs. $5.4 \%, p=0.009$ ). Patients requiring conversion experienced a higher rate of postoperative complications ( $38.5 \%$ vs. $12.4 \%, p=0.008$ ). There were no significant differences in terms of resection type and American Joint Committee on Cancer (AJCC) 8th stage. Major liver resection involving $>3$ segments and percentage of liver cirrhosis identified via pathology were more frequent in the conversion group, but these differences were not statistically significant. The R0 resection rate was significantly higher in the Lap group $(96.0 \%$

Table 3. Comparison of perioperative and pathologic outcomes between the Lap and Conversion groups

\begin{tabular}{|c|c|c|c|}
\hline Variable & Lap group $(n=299)$ & Conversion group $(n=13)$ & $p$ value \\
\hline Operation time (min) & $182.03 \pm 105.65$ & $300.00 \pm 142.08$ & $<0.001$ \\
\hline Estimated blood loss (mL) & $411.35 \pm 614.33$ & $1,596.15 \pm 1,604.87$ & 0.021 \\
\hline Blood transfusion & $16(5.4)$ & $3(23.1)$ & 0.009 \\
\hline Postoperative hospital stay (day) & $6.48 \pm 6.71$ & $10.38 \pm 5.69$ & 0.040 \\
\hline Postoperative complication & 37 (12.4) & $5(38.5)$ & 0.008 \\
\hline CD grade I & $9(3.0)$ & $0(0)$ & \\
\hline CD grade $\|$ & $7(2.3)$ & $3(23.1)$ & \\
\hline CD grade III & $21(7.2)$ & $2(15.4)$ & \\
\hline Type of resection & & & 0.553 \\
\hline Tumorectomy & $138(46.2)$ & $5(38.5)$ & \\
\hline Segmentectomy & $56(18.7)$ & $3(23.1)$ & \\
\hline Bisegmentectomy & $4(1.3)$ & $0(0)$ & \\
\hline Left lateral sectionectomy & $72(24.1)$ & $2(15.4)$ & \\
\hline Left hemihepatectomy & $29(9.7)$ & $3(23.1)$ & \\
\hline Major resection & $29(9.7)$ & $3(23.1)$ & 0.138 \\
\hline Pringle maneuver & $97(32.4)$ & $10(76.9)$ & 0.001 \\
\hline Liver cirrhosis & $180(60.2)$ & $11(84.6)$ & 0.079 \\
\hline Resection status & & & $<0.001$ \\
\hline RO & $287(96.0)$ & $11(84.6)$ & \\
\hline $\mathrm{R} 1$ & $12(4.1)$ & $2(15.4)$ & \\
\hline AJCC 8th stage & & & 0.102 \\
\hline No residual tumor & $7(2.3)$ & $0(0)$ & \\
\hline । & $167(55.9)$ & $5(38.5)$ & \\
\hline$\|$ & $108(36.1)$ & $5(38.5)$ & \\
\hline III & $17(5.7)$ & $3(23.1)$ & \\
\hline
\end{tabular}

Values are presented as mean \pm standard deviation or number (\%).

Lap group, the patients underwent laparoscopic liver resection; Conversion group, the patients underwent unplanned conversion. Presence of liver cirrhosis was confirmed at the postoperative pathology report.

CD, Clavien-Dindo classification; R0, negative resection margin; R1, positive microscopic margin; AJCC, American Joint Committee on Cancer. 
Table 4. Multivariate logistic regression analysis to predict risk factors associated with unplanned conversion

\begin{tabular}{|c|c|c|}
\hline Variable & OR (95\% Cl) & $p$ value \\
\hline Age & 1.009 (0.941-1.083) & 0.797 \\
\hline \multicolumn{3}{|l|}{ Sex } \\
\hline Male & Reference & \\
\hline Female & $0.144(0.010-1.986)$ & 0.148 \\
\hline Body mass index & $1.070(0.895-1.279)$ & 0.459 \\
\hline Platelet count & 0.990 (0.979-1.002) & 0.115 \\
\hline Tumor size & 1.349 (1.048-1.737) & 0.020 \\
\hline \multicolumn{3}{|l|}{ No. of tumors } \\
\hline Solitary & Reference & \\
\hline Multiple & $5.948(1.451-24.391)$ & 0.013 \\
\hline \multicolumn{3}{|l|}{ Extent of resection } \\
\hline Minor & Reference & \\
\hline Major & $2.131(0.087-52.236)$ & 0.643 \\
\hline Other organ invasions & $15.324(1.798-130.585)$ & 0.013 \\
\hline
\end{tabular}

$\mathrm{OR}$, odds ratio; $\mathrm{Cl}$, confidence interval.

vs. $84.6 \%, p<0.001)$.

\section{Risk factors for conversion}

The results of the multivariate logistic regression analysis are presented in Table 4. Larger tumor size (odds ratio [OR], 1.349; $p$ $=0.020$ ), multiple tumors (OR, 5.948; $p=0.013$ ), and the presence of other organ invasion (OR, 15.324; $p=0.013)$ were independently associated with conversion. Age, BMI, and platelet count did not affect conversion. Regarding the extent of resection, major liver resection in AL liver segments was not a risk factor for conversion.

\section{Planned open vs. conversion}

We compared the Conversion and Open groups. The preoperative factors and patient characteristics are compared in Table 5 . The two groups were similar in terms of preoperative factors, except that multiple tumors were more frequent (38.5\% vs. $14.5 \%$, $p=0.044)$ in the Conversion group. Table 6 shows the perioperative and pathologic outcomes of the two groups. In patients who underwent unplanned conversion, the mean operation time was longer (300.00 \pm 142.08 minutes vs. $222.42 \pm 88.10$ minutes, $p=$ $0.012)$ and the estimated blood loss was greater $(1,596.15 \pm 1,604.87$ $\mathrm{mL}$ vs. $812.50 \pm 977.66 \mathrm{~mL} ; p=0.024$ ) than in the Open group. Blood transfusion rate, duration of postoperative hospital stay, postoperative complication rate, extent of resection, AJCC 8th stage, and R0 status were comparable between the two groups.

\section{Long-term oncologic outcomes: disease-free survival and overall survival}

The long-term oncologic outcomes of the three groups were analyzed in terms of OS and DFS (Fig. 1). The median follow-up periods for the Lap, Conversion, and Open groups were 49, 17, and 32 months, respectively. DFS was significantly different between the three groups $(p<0.001)$ (Fig. 1A). Subgroup analysis showed that the Conversion group (median of 7 months) had a significantly lower DFS compared to the Lap group (vs. median of 30 months, $p=0.001$ ), while the DFS was similar to that of the Open group (vs. median of 11 months, $p=0.479$ ). DFS was significantly higher in the Lap group than in the Open group (median of 30 months vs. 11 months, $p<0.001$ ).

There was also a significant difference in OS between the three groups $(p=0.004)$ (Fig. 1B). The Conversion group showed a similar OS (median of 17 months) compared to the Lap (median of 49 months, $p=0.142$ ) and Open (median of 32 months, $p=$ $0.961)$ groups. The Lap group had a significantly higher OS than the Open group (median of 49 months vs. 32 months, $p=0.001$ ).

\section{DISCUSSION}

Most previous studies on conversion during minimally invasive liver resection (MILR) included benign or malignant lesions located in all segments of the liver [10,11,13-18]. However, compared to laparoscopy for AL segments, the laparoscopic approach for PS segments is challenging with high conversion rates and is only recommended for experienced surgeons [3]. Moreover, underlying liver cirrhosis is more common in patients with HCC than in metastatic lesions or benign lesions, which increases the risk of excessive intraoperative bleeding. Accordingly, these factors might have caused bias in the assessment of perioperative outcomes and risk factors for unplanned conversion. Furthermore, there are only a few studies on the long-term oncologic outcomes of conversion during LLR for HCC, and the available results are controversial $[13,14,17]$. To the best of our knowledge, ours is the first study to analyze the long-term implications and risk factors for unplanned conversion in LLR for HCC located in AL segments, for which the laparoscopic approach is considered the standard procedure.

In our study, the conversion rate was $4.3 \%$, which is compatible with a previous review that reported a conversion rate of $<5 \%$ for standard LLR [19]. The most common cause of conversion was bleeding (69.2\%), which is comparable to the results of previous studies $[10-14,18,19]$. Previous studies revealed that unplanned conversion is associated with poor perioperative outcomes $[10,11,13-18]$, as noted in the current study, in terms of lon- 
Table 5. Comparison of preoperative characteristics between the Open and Conversion groups

\begin{tabular}{|c|c|c|c|}
\hline Variable & Open group & Conversion group & $p$ value \\
\hline No. of patients & 62 & 13 & \\
\hline Age (yr) & $61.52 \pm 11.11$ & $57.62 \pm 9.13$ & 0.241 \\
\hline Sex & & & 0.677 \\
\hline Male & $52(83.9)$ & $12(92.3)$ & \\
\hline Female & $10(16.1)$ & $1(7.7)$ & \\
\hline Body mass index $\left(\mathrm{kg} / \mathrm{m}^{2}\right)$ & $22.78 \pm 3.32$ & $23.72 \pm 3.21$ & 0.356 \\
\hline Child-Pugh classification & & & 0.582 \\
\hline$A$ & $56(90.3)$ & $13(100)$ & \\
\hline B & $6(9.7)$ & $0(0)$ & \\
\hline C & $0(0)$ & $0(0)$ & \\
\hline Hepatitis & & & 0.618 \\
\hline HBV & $40(64.5)$ & $10(76.9)$ & \\
\hline $\mathrm{HCV}$ & $2(3.2)$ & $0(0)$ & \\
\hline Both positive & $0(0)$ & $0(0)$ & \\
\hline Both negative & $20(32.3)$ & $3(23.1)$ & \\
\hline History of abdominal surgery & $12(19.4)$ & $1(7.7)$ & 0.444 \\
\hline Alpha-fetoprotein & $4,351.10 \pm 14,015.75$ & $290.89 \pm 449.46$ & 0.457 \\
\hline Prior TACE & $18(29.0)$ & $4(36.4)$ & 0.724 \\
\hline Prior RFA & $8(12.9)$ & $0(0)$ & 0.598 \\
\hline Tumor size (cm) & $5.45 \pm 4.29$ & $4.14 \pm 2.75$ & 0.296 \\
\hline No. of tumors & & & 0.044 \\
\hline Solitary & $53(85.5)$ & $8(61.5)$ & \\
\hline Multiple & $9(14.5)$ & $5(38.5)$ & \\
\hline Vascular invasion & $8(12.9)$ & $0(0)$ & 0.717 \\
\hline Other organ invasions ${ }^{a}$ ) & $6(9.8)$ & $2(15.4)$ & 0.624 \\
\hline
\end{tabular}

Values are presented as number only, number (\%), or mean \pm standard deviation.

Open group, the patients underwent planned open liver resection; Conversion group, the patients underwent unplanned conversion.

HBV, hepatitis B virus; HCV, hepatitis C virus; TACE, transarterial chemoembolization; RFA, radiofrequency ablation.

${ }^{a}$ Other organ invasions imply the cases in which hepatocellular carcinoma involves organs other than the liver.

ger operation time, greater intraoperative blood loss with higher transfusion rate, longer hospital stay, and higher postoperative complication rate. Our results were anticipated because conversion involves laparotomy, which directly offsets the advantages of minimally invasive surgery, such as smaller scarring, early recovery, and lower complication rate. In addition, excessive blood loss and blood transfusion are known to be associated with worse postoperative and oncologic outcomes [12,20,21], along with longer operation time [22,23]. Several studies have suggested that an early decision for conversion could reduce blood loss and mitigate the adverse effects of conversion on postoperative outcomes, noting that conversion should not be viewed as failure of minimally invasive surgery $[1,3,24]$.

One of the notable findings in our study was that the R0 resection rate was significantly lower in patients who experienced unplanned conversion. In a study by Stiles et al. [17], the conversion group showed a higher rate of positive margins, although this finding was not statistically significant. However, another study reported similar R0 status in the conversion and MILR groups [14]. Lee et al. [25] speculated that intraoperative bleeding can compromise the visibility of the operative field and stain the cut surface, making it difficult to secure a negative resection margin.

In this study, patients who experienced unplanned conversion showed significantly worse DFS compared to patients who un- 
Table 6. Perioperative and pathologic outcomes in the Open and Conversion groups

\begin{tabular}{|c|c|c|c|}
\hline Variable & Open group $(n=62)$ & Conversion group $(n=13)$ & $p$ value \\
\hline Operation time (min) & $222.42 \pm 88.103$ & $300.00 \pm 142.08$ & 0.012 \\
\hline Estimated blood loss (mL) & $812.50 \pm 977.66$ & $1,596.15 \pm 1,604.87$ & 0.024 \\
\hline Blood transfusion & $14(22.6)$ & $3(23.1)$ & 0.969 \\
\hline Postoperative hospital stay (day) & $11.82 \pm 9.31$ & $10.38 \pm 5.69$ & 0.594 \\
\hline Postoperative complication & $17(27.0)$ & $5(38.5)$ & 0.521 \\
\hline CD grade I & $2(3.2)$ & $0(0)$ & \\
\hline CD grade II & $4(6.5)$ & $3(23.1)$ & \\
\hline CD grade III & $11(17.5)$ & $2(15.4)$ & \\
\hline Type of resection & & & 0.512 \\
\hline Tumorectomy & $15(24.2)$ & $5(38.5)$ & \\
\hline Segmentectomy & $16(25.8)$ & $3(23.1)$ & \\
\hline Bisegmentectomy & $3(4.8)$ & $0(0)$ & \\
\hline Left lateral sectionectomy & $4(6.5)$ & $2(15.4)$ & \\
\hline Left hemihepatectomy & $24(38.7)$ & $3(23.1)$ & \\
\hline Major resection & $24(38.7)$ & $3(23.1)$ & 0.485 \\
\hline Pringle maneuver & $31(51.7)$ & $10(76.9)$ & 0.128 \\
\hline Liver cirrhosis & $41(67.2)$ & $11(84.6)$ & 0.213 \\
\hline Resection status & & & 0.910 \\
\hline Ro & $53(88.3)$ & $11(84.6)$ & \\
\hline $\mathrm{R} 1$ & $9(11.7)$ & $2(15.4)$ & \\
\hline AJCC 8th stage & & & 0.627 \\
\hline No residual tumor & $1(1.6)$ & $0(0)$ & \\
\hline । & $17(27.4)$ & $5(38.5)$ & \\
\hline$\|$ & $20(32.3)$ & $5(38.5)$ & \\
\hline III & $24(38.7)$ & $3(23.1)$ & \\
\hline
\end{tabular}

Values are presented as mean \pm standard deviation or number (\%).

Open group, the patients underwent planned open liver resection; Conversion group, the patients underwent unplanned conversion. Presence of liver cirrhosis was confirmed at the postoperative pathology report.

$\mathrm{CD}$, Clavien-Dindo classification; R0, negative resection margin; R1, positive microscopic margin; AJCC, American Joint Committee on Cancer.

derwent successful LLR, while OS was comparable between the two groups. Only a few previous studies have assessed the longterm oncologic outcomes of unplanned conversion, and available data are controversial. Stiles et al. [17] demonstrated that conversion during major hepatectomy was associated with worse OS, while Lee et al. [14] reported similar long-term outcomes in terms of OS and DFS between conversion and laparoscopy groups. One possible explanation for the worse DFS is that a higher rate of positive resection margins associated with unplanned conversion might have facilitated recurrence. In addition, excessive bleeding during surgery might have facilitated the spillage of tumor cells into the intraabdominal cavity or systemic circulation, which could promote recurrence [20].

Several studies have analyzed risk factors for unplanned conversion. Lee et al. [14] reported that right-sided sectionectomy, central bisectionectomy, and tumor size were risk factors. According to Stiles et al. [17], tumor size was the most significant predictor of conversion. Troisi et al. [18] noted that resection involving PS segment was an independent risk factor for conversion. In a retrospective study of 223 patients, Cauchy et al. [10] reported that tumor diameter of $>10 \mathrm{~cm}$, age of $>75$ years, BMI of $>28 \mathrm{~kg} / \mathrm{m}^{2}$, and biliary reconstruction were risk factors for conversion. In a multicenter review of 2,961 cases, PS location, extent of resection, neoadjuvant chemotherapy, previous liver 

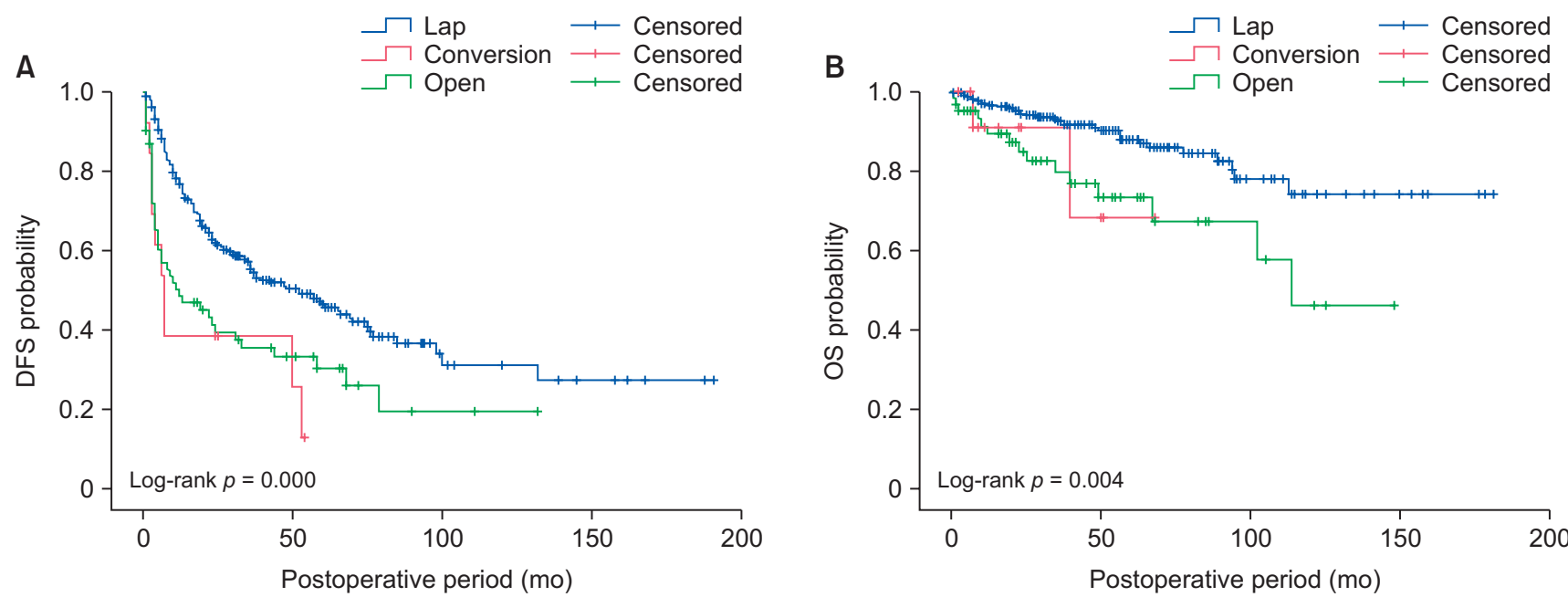

Fig. 1. (A) Diease-free survival (DFS) rate and (B) overall survival (OS) rate of patients with hepatocellular carcinoma located in anterolateral segments after liver resection. Lap group, the patients underwent laparoscopic liver resection; Conversion group, the patients underwent unplanned conversion; Open group, the patients underwent planned open liver resection.

resection, and malignant lesions were revealed as risk factors [13]. In the current study, independent risk factors for unplanned conversion were large tumor size, multiple tumors, and invasion of other organs. Large tumor size is a well-known risk factor, which intuitively requires larger and more resection planes along with multiplicity of tumors, resulting in a higher risk of bleeding. In patients with other organ invasions, increased operative difficulty is anticipated, thus elevating the risk of conversion.

This study has several limitations. First, it was a single-institutional, retrospective, nonrandomized study, which may have introduced selection bias and confounding effects. However, definite selection criteria for laparotomy or MILR for HCC have not been established, and this made it difficult to perform a randomized control study. Second, the number of patients who experienced unplanned conversion was relatively small because of the low conversion rate (4.3\%). Since our center is specialized and experienced in LLR, the results may not be generalizable to other centers. Therefore, global prospective multicenter studies are required.

In conclusion, patients who experienced unplanned conversion during LLR for HCC located in AL segments showed poor perioperative and long-term outcomes compared to those who underwent planned laparoscopic and OLR. A large tumor size, multiple tumors, and other organ invasion were noted as independent risk factors for conversion. Therefore, planned OLR should be considered in patients with risk factors.

\section{NOTES}

\section{Ethical statements}

This study was performed in accordance with the Declaration of Helsinki and approved by the Institutional Review Board of our hospital according to the guidelines for human subjects' research with a waiver of informed consent (No. B-2110-714-105).

\section{Author's contributions}

Conceptualization, Methodology: JYC

Data curation: HS

Investigation: $\mathrm{BL}, \mathrm{MK}, \mathrm{YJ}$

Project administration: BL

Supervision: HSH

Validation: YSY, HWL, JSL

Writing-original draft: $\mathrm{HS}$

Writing-review \& editing: JYC

All authors read and approved the final manuscript.

\section{Conflict of interest}

All authors have no conflicts of interest to declare.

\section{Funding/support}

None. 


\section{ORCID}

Hyojin Shin, https://orcid.org/0000-0002-8661-6716

Jai Young Cho, https://orcid.org/0000-0002-1376-956X

Ho-Seong Han, https://orcid.org/0000-0001-9659-1260

Yoo-Seok Yoon, https://orcid.org/0000-0001-7621-8557

Hae Won Lee, https://orcid.org/0000-0002-3312-9295

Jun Suh Lee, https://orcid.org/0000-0001-9487-9826

Boram Lee, https://orcid.org/0000-0003-1567-1774

Moonhwan Kim, https://orcid.org/0000-0003-2772-0836

Yeongsoo Jo, https://orcid.org/0000-0002-9385-3058

\section{REFERENCES}

1. Cheung TT, Han HS, She WH, et al. The Asia Pacific consensus statement on laparoscopic liver resection for hepatocellular carcinoma: a report from the 7th Asia-Pacific Primary Liver Cancer Expert Meeting held in Hong Kong. Liver Cancer 2018;7:28-39.

2. Chang S, Laurent A, Tayar C, Karoui M, Cherqui D. Laparoscopy as a routine approach for left lateral sectionectomy. Br J Surg 2007;94:5863.

3. Buell JF, Cherqui D, Geller DA, et al. The international position on laparoscopic liver surgery: the Louisville Statement, 2008. Ann Surg 2009;250:825-830.

4. Wakabayashi G, Cherqui D, Geller DA, et al. Recommendations for laparoscopic liver resection: a report from the second international consensus conference held in Morioka. Ann Surg 2015;261:619-629.

5. Sotiropoulos GC, Prodromidou A, Machairas N. Meta-analysis of laparoscopic vs open liver resection for hepatocellular carcinoma: the European experience. J BUON 2017;22:1160-1171.

6. Xiong JJ, Altaf K, Javed MA, et al. Meta-analysis of laparoscopic vs open liver resection for hepatocellular carcinoma. World J Gastroenterol 2012;18:6657-6668.

7. Cho JY, Han HS, Yoon YS, Shin SH. Feasibility of laparoscopic liver resection for tumors located in the posterosuperior segments of the liver, with a special reference to overcoming current limitations on tumor location. Surgery 2008;144:32-38.

8. Yoon YS, Han HS, Cho JY, Ahn KS. Total laparoscopic liver resection for hepatocellular carcinoma located in all segments of the liver. Surg Endosc 2010;24:1630-1637.

9. Guro H, Cho JY, Han HS, Yoon YS, Choi Y, Periyasamy M. Current status of laparoscopic liver resection for hepatocellular carcinoma. Clin Mol Hepatol 2016;22:212-218.

10. Cauchy F, Fuks D, Nomi T, et al. Risk factors and consequences of conversion in laparoscopic major liver resection. Br J Surg 2015;102: 785-795.

11. Goh BK, Chan CY, Wong JS, et al. Factors associated with and outcomes of open conversion after laparoscopic minor hepatectomy: initial experience at a single institution. Surg Endosc 2015;29:26362642.

12. Gupta R, Fuks D, Bourdeaux C, et al. Impact of intraoperative blood loss on the short-term outcomes of laparoscopic liver resection. Surg Endosc 2017;31:4451-4457.

13. Halls MC, Cipriani F, Berardi G, et al. Conversion for unfavorable intraoperative events results in significantly worse outcomes during laparoscopic liver resection: lessons learned from a multicenter review of 2861 cases. Ann Surg 2018;268:1051-1057.

14. Lee JY, Rho SY, Han DH, Choi JS, Choi GH. Unplanned conversion during minimally invasive liver resection for hepatocellular carcinoma: risk factors and surgical outcomes. Ann Surg Treat Res 2020; 98:23-30.

15. Silva JP, Berger NG, Yin Z, et al. Minimally invasive hepatectomy conversions: an analysis of risk factors and outcomes. HPB (Oxford) 2018;20:132-139.

16. Stiles ZE, Behrman SW, Glazer ES, et al. Predictors and implications of unplanned conversion during minimally invasive hepatectomy: an analysis of the ACS-NSQIP database. HPB (Oxford) 2017;19:957-965.

17. Stiles ZE, Glazer ES, Deneve JL, Shibata D, Behrman SW, Dickson PV. Long-term implications of unplanned conversion during laparoscopic liver resection for hepatocellular carcinoma. Ann Surg Oncol 2019;26:282-289.

18. Troisi RI, Montalti R, Van Limmen JG, et al. Risk factors and management of conversions to an open approach in laparoscopic liver resection: analysis of 265 consecutive cases. HPB (Oxford) 2014;16:7582.

19. Nguyen KT, Gamblin TC, Geller DA. World review of laparoscopic liver resection-2,804 patients. Ann Surg 2009;250:831-841.

20. Katz SC, Shia J, Liau KH, et al. Operative blood loss independently predicts recurrence and survival after resection of hepatocellular carcinoma. Ann Surg 2009;249:617-623.

21. Khuri SF, Henderson WG, DePalma RG, et al. Determinants of longterm survival after major surgery and the adverse effect of postoperative complications. Ann Surg 2005;242:326-343.

22. Fan ST, Lo CM, Liu CL, et al. Hepatectomy for hepatocellular carcinoma: toward zero hospital deaths. Ann Surg 1999;229:322-330.

23. Jackson TD, Wannares JJ, Lancaster RT, Rattner DW, Hutter MM. Does speed matter?: the impact of operative time on outcome in laparoscopic surgery. Surg Endosc 2011;25:2288-2295.

24. Costi R, Scatton O, Haddad L, et al. Lessons learned from the first 100 laparoscopic liver resections: not delaying conversion may allow reduced blood loss and operative time. J Laparoendosc Adv Surg Tech A 2012;22:425-431.

25. Lee B, Han HS, Yoon YS. Impact of preoperative malnutrition on postoperative long-term outcomes of patients with pancreatic head cancer. Ann Surg 2021;2:e047. 